\title{
Un mástil para el arte contemporáneo. La colección Engelman Ost en el campo artístico local
}

\author{
A mast for contemporary art. \\ The Engelman-Ost collection in the local artistic field
}

\section{Carolina Porley*}

\footnotetext{
* Licenciada en Comunicación Periodística (Universidad ORT, Montevideo), profesora de Historia (Instituto de Profesores Artigas, Montevideo). Docente de Historia del Arte en bachillerato. Periodista en semanario Brecha. $\triangle$ caro.porley@gmail.com https://orcid.org/0000-00030664-7211
}

RECIBIDO: [12.9.2017]

ACEPTADO: [1.11.2017]

\begin{abstract}
Resumen
El artículo analiza la colección Engelman-Ost, principal colección de arte contemporáneo de Uruguay, poniendo el foco en el peso del coleccionismo en el campo artístico local y en su influencia en los procesos de circulación y promoción del arte contemporáneo. Se analiza la colección como representativa del nuevo coleccionismo artístico surgido en los años setenta, diferenciándolo del coleccionismo moderno, característico de la primera mitad del siglo Xx. Con base en una entrevista a Clara Ost y en el trabajo con el archivo digital de la colección, se estudian el modelo de consumo artístico seguido por los coleccionistas, el perfil de la colección, su guion curatorial y el sentido que sus propietarios dan al conjunto reunido.
\end{abstract}

Palabras clave: arte contemporáneo, Uruguay, colección de arte, usuario cultural.

\section{Abstract}

The article analyzes the Engelman-Ost Collection, Uruguay's main collection of contemporary art, focusing on this couple's role within the local art field, and their influence on the processes of circulation and promotion of contemporary art. This collection is analyzed as representative of the new way of collecting art 
that emerged in the seventies, which differs from the modern art collecting of the first half of the 20th century. Based on an interview with Clara Ost and the scrutiny of the collection's digital archive, the pattern of art consumption followed by both collectors is studied, as well as the collection's main features, its curatorial script and the meaning attributed by the collectors to the whole set.

Keywords: contemporary art, Uruguay, art collections, cultural users.

\section{Introducción}

Flagpole es una pequeña obra del artista uruguayo Fernando López Lage (Montevideo, 1964) que representa a la coleccionista Clara Ost (imagen 1). El retrato incluye una fotografía del rostro de Ost a partir de la cual surge una figura alargada, con sobretodo blanco, que juega con el título de la obra: Flagpole es el asta o mástil que sostiene una bandera. La técnica pictórica, de gruesas pinceladas e intensos colores, acentúa la fuerza expresiva del conjunto.

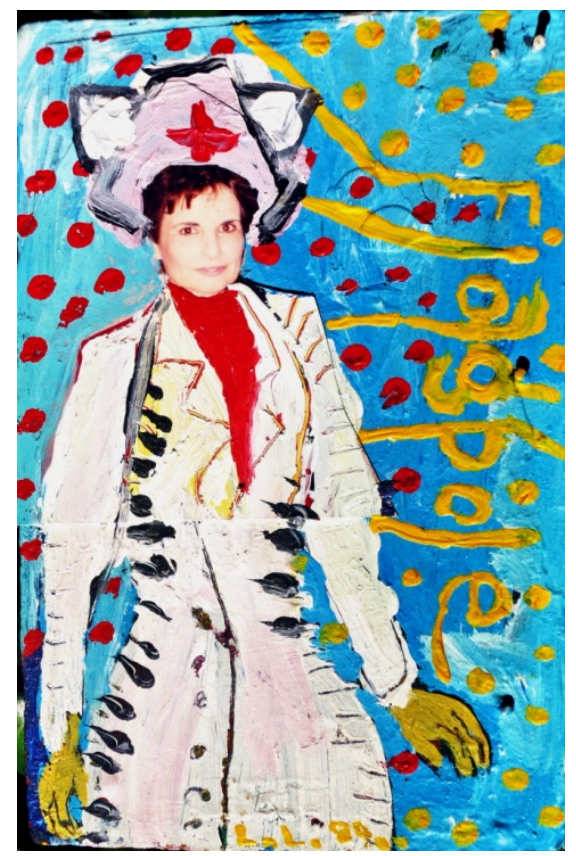

Figura 1. Flagpole (10x15cm), Fernando López Lage, 1989 (gentileza de la Colección Engelman Ost) 
La elección de la metáfora con la que el artista caracteriza a Ost puede vincularse a la función simbólica que le atribuye a la coleccionista, en cuanto sostén y divulgadora de la producción artística contemporánea. Artista visual, curador y director de la Fundación de Arte Contemporáneo (FAC), López Lage es uno de los creadores más cercanos al matrimonio de Carlos Engelman (Entre Ríos, 1934) y Clara Ost (Montevideo, 1940), dueños del principal conjunto dedicado al arte contemporáneo de Uruguay que existe en el país.

El retrato es un homenaje a Ost, a su compromiso con los artistas uruguayos, a quienes viene comprando obra desde hace 50 años. Lo hizo con particular intensidad durante la década de 1980, en tiempos en los que la mayoría de los creadores uruguayos tenía serias dificultades para difundir su trabajo, por el clima de opresión que se vivía desde la década anterior y el consiguiente deterioro del campo cultural. Por eso Flagpole puede entenderse como el agradecimiento de un joven López Lage (la obra es de 1989) al rol crucial del coleccionismo en el impulso del arte contemporáneo.

Así como López Lage reconoce el papel del coleccionismo en la validación del arte, su retrato opera como instrumento de consagración para la coleccionista, una especie de espejo donde Ost puede mirarse y reconocerse.

Diversos autores han sostenido que la necesidad de reconocimiento o autoafirmación es una de las razones principales que llevan a las personas a coleccionar. Según Werner Muensterberger (1993), una colección permite al coleccionista reafirmar su identidad, al tiempo que proyectar la imagen deseada en los demás, mientras Jean Baudrillard subraya que «la colección es un discurso para los otros, pero sobre todo es un discurso para sí mismo» (Baudrillard, 1969, p. 120).

En Flagpole ambos actores (el artista y la coleccionista) se legitiman recíprocamente.

El análisis de la obra sirve para explicar la aproximación teórica que guía este artículo. Según la noción de mundo del arte (art word), elaborada por Arthur Danto (1964) y reformulada por George Dickie (2005) en su teoría institucionalista del arte, es el conjunto de actores individuales e institucionales (museos, bienales, académicos, críticos, curadores, coleccionistas, galeristas) el que define el arte en un momento dado. Frente a esa noción se opta aquí por el concepto de campo artístico de Pierre Bourdieu, formulado inicialmente en 1966. El campo es un espacio social en el que se hallan situados los que producen las obras y su valor:

Ese campo (literario, artístico, científico) no es ni un «medio» en el sentido vago de «contexto» o de «social background» [...] ni siquiera lo que comúnmente se entiende por «medio literario» o «medio artístico», es decir, un universo de relaciones personales entre los artistas o los escritores, sino un campo de fuerzas que actúan sobre todos los que entran en ese espacio y de maneras diferentes 
según la posición que ocupan en él [...], a la vez que un campo de luchas que procuran transformar ese campo de fuerzas. Ese espacio relativamente autónomo es, en efecto, la mediación específica, casi siempre olvidada por la historia social y la sociología del arte, a través de la cual se ejercen sobre la producción cultural las determinaciones externas. (Bourdieu, 1989-1990, p. 21)

La noción tiene una dimensión histórica, al considerar ese sistema de relaciones y posiciones como algo no congelado sino que cambia según la correlación de fuerzas y luchas entre los actores del campo. Así contribuye a dejar atrás tanto las miradas que otorgan a los ámbitos de producción artística un alto grado de autonomía como los planteos reduccionistas que vinculan directamente la creación artística con el contexto institucional, social, político, económico, reduciéndola a un mero reflejo.

Con el consumo artístico puede hacerse un análisis similar. El coleccionismo no debería verse como una práctica de personajes singulares que consumen arte motivados por deseos personales y gustos meramente subjetivos. Tampoco es el coleccionista un consumidor pasivo, que adquiere lo que el mercado, su clase social o los dictados de la moda le inducen a adquirir. Ambos abordajes parecen reduccionistas. Estos actores participan en un campo artístico asumiendo posiciones y vinculándose con otros (artistas, críticos, galeristas) que luchan dentro de ese campo para imponer sus criterios. Y así como integran ese campo, reflejando las tendencias dentro de él, ejercen en él su propia influencia.

En un sentido similar, Roger Chartier (1992) ha cuestionado la división entre producción artística y consumo cultural, como si solo la primera constituyera una práctica intelectual activa y el consumo se redujera a un mero reflejo pasivo. Para él no existe una verdad única y permanente de la obra de arte (que estaría implícita en ella o en su autor), sino que cada vez que la obra es reproducida, interpretada o exhibida se crea para ella un nuevo sentido, lo que es un acto creativo del divulgador o consumidor. Siguiendo este abordaje, el coleccionista es también un creador, y su trabajo podría asociarse al del curador, porque crea un guion para las obras reunidas, a las que da un nuevo sentido y valor, observables, por ejemplo, en los criterios de exhibición que elige, en la forma de ordenar las piezas según sus propias pautas, jerarquías y asociaciones.

\section{Coleccionismo moderno y contemporáneo}

Para avanzar en el perfil de la colección Engelman Ost y en su papel en el campo artístico local, conviene primero establecer una distinción entre un coleccionismo moderno y un nuevo coleccionismo o coleccionismo contemporáneo. 
Independientemente del tipo de obra objeto de acopio, y más bien considerando los intereses y objetivos del coleccionista, se puede reconocer como coleccionismo moderno aquel que ha sido vivido con un sentido pedagógico y político, en el marco de un proyecto civilizatorio moderno y de afirmación de la identidad del Estado-nación. Estos coleccionistas no solo procuraron la distinción social (Bourdieu, 1998), sino que se creían con el derecho (y la obligación) de educar la cultura artística del pueblo, transmitiendo a través de los conjuntos coleccionados determinadas narrativas culturales e identitarias.

En general, se trata de coleccionistas que concibieron la proyección pública de sus acervos, los cuales dejarían el ámbito privado para legitimarse en el dominio público. Su misión era formar el patrimonio artístico público, donando, legando o vendiendo sus colecciones al Estado.

En Uruguay este coleccionismo moderno se reconoce fuertemente en la primera mitad del siglo xx, en personalidades como el matrimonio de Alejo Rossell y Rius y Dolores Pereira, cuya pinacoteca, donada a la Intendencia de Montevideo en 1912, constituyó el acervo inicial del museo municipal de Bellas Artes. También en la familia Ortiz de Taranco, que tras la muerte del coleccionista, Félix Ortiz de Taranco (18661940), donó en 1942 al Ministerio de Instrucción Pública el mobiliario y la pinacoteca, reunidos en su residencia, con la condición de que se constituyera allí un museo de artes decorativas que mantuviera vivo el legado familiar.

Más significativo aún es el legado realizado vía testamento por el empresario Fernando García Casalia (1887-1945), de una multiplicidad de bienes y colecciones y la mayor pinacoteca privada cedida al Estado. Eran 350 obras originales e incluían la más importante y cuantiosa colección de Juan Manuel Blanes jamás reunida (Porley, 2017).

Para el caso de Argentina, la historiadora María Isabel Baldasarre (2006) ha identificado un primer coleccionismo moderno de tipo burgués, entre el último tercio del siglo XIX y principios del XX, el cual consideraba que la promoción de las artes era necesaria para construir una nación civilizada y moderna, según el canon europeo occidental. Esos coleccionistas no reflejaron la modernidad, sino que contribuyeron a su construcción, impulsados por un sentido de trascendencia corporizado en el destino final asignado a sus colecciones, las cuales ingresaron a los museos estatales y provinciales.

En Uruguay ese coleccionismo no coincide con la etapa fundacional del Estado moderno (primera modernización del último tercio del siglo XIX), sino con una etapa refundacional como fue la vivida en las décadas en torno al Centenario (1910-1940). En ese contexto histórico se reconoce un campo intelectual donde coexistían distintos esfuerzos de reafirmación identitaria. Uno cosmopolita, de espaldas al pasado y que apostaba a una acelerada apertura al mundo, y otros que buscaban rescatar las raíces culturales e identitarias de la nación, reivindicando la tradición y denunciando las consecuencias deshistorizantes y alienantes de la modernización. Desde estas miradas se promovían distintas narrativas culturales e identitarias que permearon el consumo 
cultural de las clases altas: el cosmopolitismo, presente por ejemplo en colecciones como las de Rossell y Rius-Pereira y Ortiz de Taranco; el hispanismo, también en la colección Ortiz de Taranco, Carlos Reyles y Fernando García; el criollismo, de las colecciones de García, Roberto Bouton, Roberto Pietracaprina, Carlos Mac Coll y Alejandro Gallinal; y el indigenismo, en los acervos prehispánicos de Gallinal, Carlos Seijo o José María Castellanos.

Todos los conjuntos mencionados fueron reunidos entre 1910 y 1940 aproximadamente y cedidos en parte o en su totalidad a instituciones estatales (museos nacionales y municipales, históricos y de arte). Se trató de un coleccionismo que coincidió con la expansión de la esfera de acción del Estado en materia cultural y artística, con la creación del Museo Nacional de Bellas Artes y del Museo Histórico Nacional en 1911, del Museo municipal de Bellas Artes y del SODRE en 1929, del coro (1934) y del cuerpo de baile (1935) del Estado, de la Comisión Nacional de Bellas Artes y del Centro de Exposiciones de Montevideo Subte (1936), de los Salones Nacionales de Artes Plásticas (1937) y de los salones municipales (1940), entre otros hitos.

Eran coleccionistas que estaban imbuidos de lo que Gerardo Caetano (2010) ha llamado una cultura estatista. Que vivieron y murieron en tiempos de consolidación del ámbito público y de la esfera de acción de un Estado que permeó cultualmente a la elite social que necesitó consagrarse en ese espacio público y oficial, como benefactora y constructora de la cultura nacional.

En ese marco, se explica que hayan buscado un espejo público para sus conquistas privadas. Si tener una colección de arte aseguraba la distinción social — por el capital simbólico y el carácter enclasante de esos bienes-, que el Estado la hiciera suya y la elevara a la condición de acervo nacional otorgaba, además, poder en términos de hegemonía cultural.

El matrimonio Engelman Ost, que comenzó su colección en 1963, forma parte de un nuevo tipo de coleccionismo, que se caracteriza, entre otros aspectos, por redefinir su relación con el ámbito público y estatal.

El optimismo estatista del coleccionismo moderno contrasta con el escepticismo que permeó a una nueva generación de coleccionistas, cuyas acciones como promotores culturales y amantes del arte no pasan por gestos de desprendimientos en favor del Estado, sino por montar y dirigir sus propias instituciones, creando nuevos circuitos y espacios para exhibir y divulgar sus colecciones y promover a los artistas de su preferencia.

Si bien mantienen la intención pedagógica, en el sentido de difundir lo que consideran valioso en materia artística y de actuar como promotores de artistas y tendencias dentro del arte que consideran válido, esta se traduce en la creación de fundaciones o galerías, en la apertura de sus propios museos o centros de exhibición, en el financiamiento de becas de formación o premios privados a artistas emergentes, en la creación de revistas, ferias de arte o bienales, entre otras medidas. 
Este nuevo coleccionismo puede remontarse a la década de 1960, aunque cobró fuerza en las de 1980 y 1990. Recuérdese la creación en 1962 del Museo de Arte Precolombino, fundado por Francisco Matto para mostrar su conjunto de piezas prehispánicas. La historia de ese acervo, del legado condicional al Estado tras la muerte del artista y de la recuperación de la colección por la familia (que revocó la donación por incumplimiento) es un triste ejemplo del escepticismo mencionado.

Otro ejemplo temprano es el del artista Jorge Páez Vilaró (1922-1994) y su Museo de Arte Americano de Maldonado (MAAM), institución que creó en 1973. Ubicado en una vieja casona del casco histórico de Maldonado, el MAAM reunió en 15 salas un conjunto variado de colecciones, que incluía la más importante dedicada al arte precolombino que existió en el país, con más de 800 piezas, y otras de arte colonial, arte popular y tribal africano y de Oceanía, así como de arte moderno y contemporáneo rioplatense.

El MAAM funcionó 20 años como centro cultural, realizando certámenes para promover a plásticos jóvenes y emergentes y poniendo sus salas a disposición de los artistas a cambio de que dejaran una obra al museo. De ese modo, Páez formó un importante conjunto de arte moderno y contemporáneo rioplatense con obras de Hugo Longa, Ignacio Iturria, Ernesto Barreda, Jorge Damiani, Américo Spósito, Washington Barcala, José Gamarra, Humberto Jaime Sánchez, Ernesto Deira, Adolfo Halty, Lino Dinetto, Miguel Ángel Pareja, Lincoln Presno, Luis A. Solari, Nicolás García Uriburu y otros. Tras su muerte, sus hijos mantuvieron un tiempo el museo, pero más tarde decidieron vender la casa y recientemente las diversas colecciones que albergaba.

La historiografía argentina ha denominado nuevo coleccionismo a un tipo particular de coleccionismo, caracterizado por su interés en el arte contemporáneo (fundamentalmente argentino), por la visibilidad dada a sus conjuntos (carácter semipúblico de las colecciones) y la alta circulación de sus obras tanto dentro como fuera de fronteras, por su accionar en el campo artístico con políticas de difusión y promoción (a partir de sus propias fundaciones y museos), por las redes transnacionales en las que participan y por su visibilidad en los medios de comunicación (Pacheco, 2002, p. 112).

También Andrea Giunta ha identificado dos cambios fuertes en el coleccionismo contemporáneo argentino: «la apertura de las colecciones privadas a la escena pública» $\mathrm{y}$ «la tendencia a generar políticas públicas desde la colección privada» (2009, p. 91).

Como ejemplo de este nuevo coleccionismo argentino pueden citarse dos casos pioneros, el del tucumano Marcos Curi (quien fundó en 1977 el Museo de Arte Contemporáneo de Balvanera, sobre la base de su propia colección) y el conjunto formado por el matrimonio de Jorge y Marion Helft, que constituye una de las colecciones más emblemáticas de arte contemporáneo del vecino país. Desde la década de 1980, los Helft vienen realizado actividades de promoción y exhibición, impulsando a artistas jóvenes, fomentando la investigación, y con un importante accionar a partir de la Fundación San Telmo. También ha sido muy estudiada la colección formada por el juez 
Gustavo Bruzzone (Cerviño, 2011; Lemus, 2014), centrada en la producción de los artistas del Centro Cultural Rojas, también con un importante trabajo de registro documental, la publicación de la revista virtual de artes visuales Ramona y la concepción de una colección semipública cuyas obras tienen circulación. Un caso aún más conocido es el conjunto de arte moderno y contemporáneo latinoamericano reunido por el millonario Eduardo Constantini, parte del cual pasó en 2001 al Museo de Arte Latinoamericano de Buenos Aires (MALBA). Este museo, que tuvo a Pacheco como curador jefe, además de exhibir su acervo, cuenta con una importante política de difusión, investigación y circulación de arte argentino y del exterior, visible en la calidad de sus muestras itinerantes.

La actividad del matrimonio Engelman Ost se acerca en varios aspectos a este nuevo coleccionismo artístico, aunque también hay diferencias sustantivas. Estos coleccionistas, que iniciaron su colección en 1963, desde el inicio le dieron a su acervo un carácter semipúblico, primero abriendo la puerta de su casa a quienes quisieran verlo y luego, a partir de 1994, exhibiendo parte de la colección en su propio espacio expositivo.

Asimismo, como se verá, los coleccionistas han buscado dinamizar y profesionalizar el campo artístico local, ocupando en él un lugar gravitante y constituyéndose en el principal ejemplo de promotores privados individuales del arte contemporáneo uruguayo. Sin embargo, la circulación de las obras de su colección ha sido muy restringida. Los Engelman Ost explican su reticencia a prestar obra en la mala experiencia (sobre todo con instituciones públicas). Tampoco contemplan la posibilidad de donar o legar su patrimonio artístico al Estado. Precisamente esta omisión de la proyección pública de su acervo marca una clara diferencia con el coleccionismo moderno.

Si bien han tejido redes con distintos actores institucionales - fundamental-mente privados- en sus esfuerzos de promocionar el arte contemporáneo, los Engelman Ost no acuden a curadores o intermediarios a la hora de decidir sus adquisiciones o difundir su colección, por lo que permanecen prácticamente al margen de los agentes que conforman el mercado local e internacional del arte. Tampoco han generado sinergias significativas con museos del país o del exterior ni con equipos de investigación (aunque en este caso la ausencia puede explicarse por la debilidad de la academia abocada a estos temas).

La Colección Engelman Ost no es la única que ha procurado actuar en el campo local del arte contemporáneo. Otros coleccionistas han hecho esfuerzos significativos de promoción. Por ejemplo, Laetitia D’Arenberg, Jorge Srur y Ricardo Murara fundaron en 2012 la Fundación Bienal de Montevideo, que ha realizado hasta la fecha tres bienales dedicadas a promover el arte contemporáneo del país y la región.

Pero los Engelman Ost son los únicos que tienen abierta una sala de exposiciones donde, además de exhibir su propia colección, ${ }^{1}$ realizan muestras itinerantes, indivi- 
duales y colectivas, de artistas, muchos de ellos jóvenes o emergentes. Precisamente su apuesta pionera por artistas no insertos en el circuito del arte legitimado, junto con acciones sostenidas de promoción de su arte, es lo que distingue a estos coleccionistas.

\section{La colección Engelman Ost}

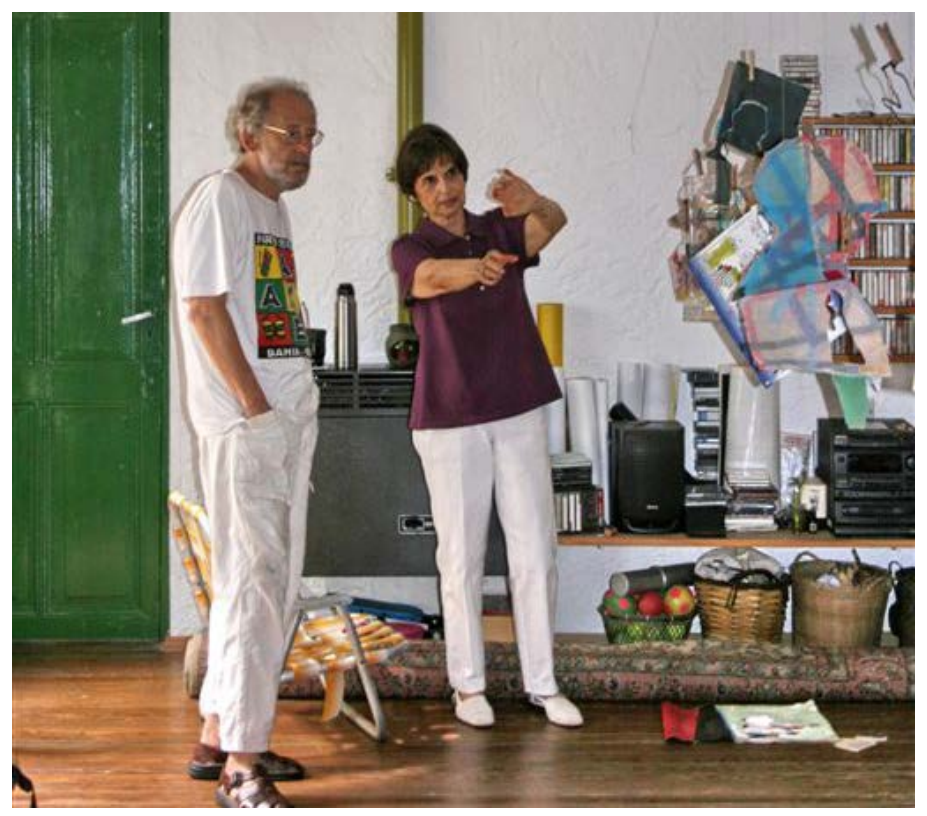

Figura 2. Clara Ost junto a Ernesto Vila en el taller del artista, febrero de 2007 (gentileza de la Colección Engelman Ost)

«Yo no entiendo a los coleccionistas», dijo Ernesto Vila al abrirle la puerta de su casa por primera vez a Clara Ost. Fue en 1986. Ost había conocido la obra del artista en una exposición en la Galería Vezelay. Le gustó, averiguó su dirección, fue y le tocó timbre, lo que dio inicio a una relación personal, intelectual y afectiva que se prolonga hasta hoy.

La anécdota ilustra la modalidad singular de acercamiento a las obras y los artistas seguida por el matrimonio Engelman-Ost como coleccionistas. No compran en galerías ni en remates, sino que se vinculan directamente con los artistas, y el contacto no se limita a la compra, sino que busca un acercamiento personal, amistoso y sostenido. 
En la suerte de ese vínculo, de esa relación con los artistas, está la clave de las presencias y ausencias en la colección.

Esta colección se fue formando siempre con los artistas, visitándolos en sus casas, en sus talleres, siguiéndolos a donde ellos iban. No voy a los remates porque de ese modo no se da ese contacto. Tengo sí algunas obras, dos o tres, que compré de forma indirecta. En un remate compré una preciosa pieza abstracta de [Óscar] García Reino que tengo en casa. La compré porque me pareció que era como el anverso de otra, muy luminosa, que ya tenía. Con respecto a las galerías, compré alguna obra en la galería Bruzzone. Eso fue al principio. Pero siempre prioricé el contacto con el artista, tratando de conocer su pensamiento e ideas que se expresan a través de la obra y viendo que fueran coherentes, más allá de los cambios en los lenguajes. Con Carlos nos hacíamos amigos del artista. No nos propusimos ser coleccionistas. Fue una cosa que nos fue resultando natural: nos gustaba la obra, nos interesaba seguir dialogando con el artista. Tratábamos de averiguar por qué a veces el artista se anticipa con su propuesta a algo que está en el aire; lo vislumbra y lo expresa a través del soporte que elige. La idea siempre fue seguir las trayectorias. Nos gusta saber en qué etapa están, que nos muestren cómo van cambiando, compremos o no (C. Ost, comunicación personal, 30 de mayo, 2013).

El testimonio arroja algunas pistas significativas sobre la forma como Ost concibe su rol. La importancia asignada al contacto con el artista, y no solo con la obra, marca una diferencia significativa respecto a otros coleccionistas que priorizan la relación con el objeto artístico, al que dan un sentido muy personal, casi independiente de su creador. Para los Engelman Ost el método de acceso a la obra es tan importante como la colección misma. Las piezas adquiridas operan como documentos del acompañamiento al artista en su trayectoria. La colección testimonia así ese seguimiento de los coleccionistas a los procesos internos de los creativos, de los caminos seguidos durante su producción creativa.

Ost afirma que no se reconoce como coleccionista, por lo que tiene esa práctica de obsesión por acumular, y prefiere definirse a partir de ese acompañamiento a los creadores: «Somos amigos de los artistas», repite.

Junto con su esposo, comenzó a formar su colección hace más de cincuenta años. Compraron su primera obra en 1963: una escultura de María Freire (1917-2015), con quien Ost tenía una relación cercana. En 1955, con 15 años, había sido alumna de Freire en un curso de Historia del Arte en preparatorios. A partir de allí surgió una amistad que se prolongó hasta la muerte de la artista. 
Yo tengo 73 años, vengo viendo exposiciones desde los 15. Estoy en esto del arte desde mucho antes de proponerme comprar una obra. Viene de cuando hice preparatorios de arquitectura, donde está el IPA ahora, y tuve a María Freire como profesora. Ella nos estimuló de una forma impensable. No era una clase de historia. Traía diapositivas de los viajes que hacía y nos enseñaba a mirar, cuáles eran los valores que teníamos que apreciar en la composición, el ritmo, el lenguaje que se usaba para la creación plástica. Cada vez que terminaba la clase decía: «Bueno, este fin de semana estas son las exposiciones que tienen que ver»... Teníamos 15 años y nos íbamos caminando al Centro desde el Palacio Legislativo, a ver esas exposiciones; luego las comentábamos. Eso fue en 1955. Después que terminó el curso, ella se ganó una beca para ir a Europa y me mandaba postales. Forjamos una linda relación. Yo visitaba su taller, que tenía con [José Pedro] Costigliolo en un sótano en Ejido. Para mí era un privilegio. Era una época en la que no se hablaba tanto del valor económico de la obra; incluso dentro de las galerías existía otro espíritu. María era crítica de arte en Acción y estábamos al tanto de las luchas que tenían los artistas... Bueno, de todo. Después, y hasta que fue posible, la seguí visitando en su casa de la rambla. (C. Ost, comunicación personal, 30 de mayo, 2013).

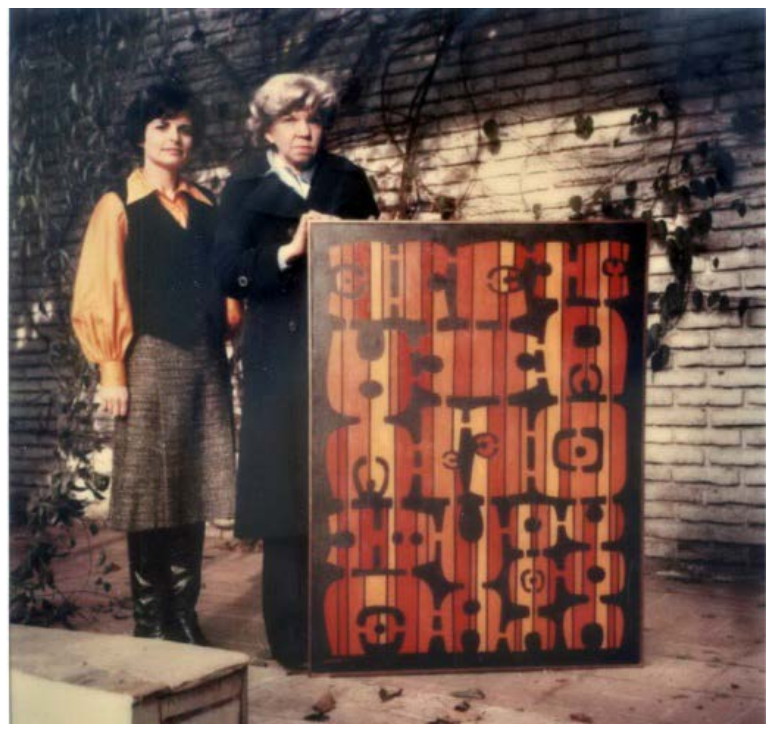

Figura 3. Clara Ost y María Freire en 1974, en la casa de la coleccionista junto a una obra de la artista (gentileza de la Colección Engelman Ost). 
El interés por el vínculo y el seguimiento del artista y su obra va más allá del deseo de coleccionar; se refleja también en el acercamiento a creadores a los que no pudieron comprarles obra: «A [Manuel] Espínola Gómez lo seguía siempre, hasta cuando propuso aquello del polifocalismo. Él venía con Hugo Nantes y otros al billar que quedaba arriba de lo que antes era la clínica de neurofisiología de mi esposo. Lo vi en el Subte y en otras exposiciones, pero nunca surgió la posibilidad de tener una obra suya. Sabía que no le gustaba vender y nunca se me ocurrió proponerle» (C. Ost, comunicación personal, 30 de mayo, 2013).

El matrimonio intensificó las adquisiciones en los años setenta y sobre todo en los ochenta, tras la restauración democrática. Hoy tiene la colección más importante de arte contemporáneo de Uruguay, con cientos de obras de más de 80 artistas, $^{2}$ aunque el número total de piezas es un dato no divulgado (Ost afirma no conocer el número con certeza; «siempre estamos comprando»).

La compra directa a los artistas, sin intermediarios comerciales, asesores ni marchands, generó una metodología de adquisición sostenida en gran parte en las redes de amistades que iban formando los coleccionistas, en las posibilidades reales de acceder directamente al artista, así como en la empatía que surgiera o no con este.

El contacto se daba de distintas formas. Había una feria del libro y había alguien con obras sobre una mesa y yo le preguntaba si podía ver alguna otra cosa más, que me interesaba lo que estaba mostrando y quería seguir investigando. Con Carlos Seveso fue así, en la feria del libro de Nancy Bacelo. Me acerqué y le pedí si me podía mostrar otras cosas que estuviera haciendo. En otros casos, como en el de Vila, había una exposición e iba y me presentaba, o pedía el teléfono y lo iba a ver a la casa. A veces, en ese abordaje, los artistas se mostraban como sorprendidos y hasta un poco fastidiados: ¿por qué iba alguien a pedir algo distinto de lo

Al 30 de mayo de 2013, la colección tenía obras de Javier Abreu , Enrique Aguerre , Gustavo Alamón, Luis Alonso, Federico Arnaud, Carlos Barea, Leo Barizzoni, Javier Bassi, Miguel Battegazzore, Daniel Behar, Pablo Bielli, Óscar Bonilla, Daniel Borlandelli, Juan Burgos, Tomás Cacheiro, Germán Cabrera, Rímer Cardillo, Eduardo Cardozo, Cristina Casabó, Julia Castagno, Carlos Costa, José Pedro Costigliolo, Roberto De León, Eduardo Díaz Yepes, Águeda Dicancro, Lacy Duarte, Magela Ferrero, Florencia Flanagan, María Freire, Daniel Gallo, Óscar García Reino, Marcelo Isarrualde, Jacqueline Lacasa, Gabriel Lema Riqué, Hugo Longa, Fernando López Lage, Marcelo Legrand, Vicente Martín, Mariana Méndez, Diana Mines, María Minetti, Carlos Musso, Hugo Nantes, Gustavo Nakle, Juan Jose Núñez, Fabián Oliver, Nerses Ounanian, Virginia Patrone, Sean Partridge, Raúl Pavlotzky, Martín Pelenur, Álvaro Pemper, Aldo Peralta, Octavio Podestá, Teresa Puppo, Duncan Quintela, Nelson Ramos, Dorys Rawak, Gabriel Regal, Manuel Rodríguez, Juliana Rosales, Federico Rubio, Agustín Sabella, Sebastián Sáez, David Salamanovich, Martín Sastre, Carlos Seveso, Carolina Sobrino, Gustavo Tabares, Santiago Tavella, Mariví Ugolino, Daniel Umpiérrez, Juan Uría, Ernesto Vila, Yudi Yudoyoko, Álvaro Zinno, del colectivo Movimiento Sexi (Julia Castagno-Paula Delgado, Federico Aguirre, Dani Umpi y Martín Sastre) y de los orfebres Olga Piria-Carlos Jauregui. Archivo documental y fotográfico de la Colección Engelman Ost. Formato CD, 30 de mayo de 2013. 
que estaba allí? Pero eso no me impidió seguir buscando lo que quería, o ver por qué me había interesado eso que vi y seguir indagando hasta obtener más información. Con Nantes, la primera vez que lo busqué fui a San José. El contacto fue a través de unos amigos y fue genial. Fuimos juntos y fue una cosa fantástica. Nos llevó hasta el gallinero, donde tenía las obras. Y a partir de allí comenzamos una amistad. Siempre íbamos a todas sus exposiciones; él pasaba por acá seguido [...] Acá no hay nada forzado, si establecíamos vínculo, bien; si no podíamos o no surgía, estaba bien también [...] Es cierto que hay artistas que podrían estar y no están, pero no fue deliberado. Es como algo que se va entretejiendo, como tener amigos. Así pasó con Longa y todos los miembros de su taller. Es muy fácil, si estás en esto, que te encuentren o vos los puedas encontrar [...] Igual, cuando me interesa la obra de un artista y no me lo presentan en una exposición o a través de amigos, pregunto dónde puedo conocer su obra, dónde lo puedo encontrar, y voy y le toco timbre (C. Ost, comunicación personal, 30 de mayo, 2013).

Frente a las ausencias, Ost explica: «Hay muchos artistas que respetamos que no están acá y es porque la colección se fue armando en base a vínculos, a una relación entre amigos, y hay veces que uno tiene más llegada o afinidad con unos que con otros en el pensamiento, la propuesta o el gesto».

En el testimonio de Ost se comprende la importancia que tuvieron estos coleccionistas en las trayectorias de muchos artistas en la década de los ochenta, años difíciles por la coyuntura política y social, así como por la pequeñez y el escaso dinamismo del circuito del arte local. Eran tiempos en los que prácticamente no había en el ámbito público (sí en el privado) espacios destinados a promover a artistas contemporáneos; los artistas emergentes no eran una prioridad del Museo Nacional de Artes Visuales, y cuando había algunos signos de apertura terminaba primando una mirada reactiva frente a ciertos lenguajes y temáticas (como cuando la censura a Óscar Larroca, en 1986, por la Intendencia de Montevideo).

La época en la que compramos más fue en los años ochenta, cuando termina la dictadura. Entonces los artistas no tenían dónde mostrar lo que hacían, dónde exponer. Nunca olvidaré las dificultades que tuvo Hugo Longa. Al final María Luisa Torrens le terminó organizando una exposición en AFE porque no se conseguía sala. Fue en 1989; yo venía comprándole obra desde los setenta. [...] Por suerte los artistas que tenemos han ido creciendo, y hoy son muy reconocidos. Pero, claro, cuando comenzamos a comprar arte contemporáneo, vamos a decir la verdad: eran pocos lo que hacían lo mismo. [...] Me alegra cuando los artistas que estaban en cero cuando los conocimos tienen una posición consolidada, ganan concursos, son docentes, están en los museos [...] Ha pasado algún crítico por acá y 
me ha dicho: «Mirá, Clara, yo no sé por qué tenés este artista acá». «Y bueno, forma parte de lo que considero válido», le respondí. Después de un tiempo aparecieron conceptos muy laudatorios acerca de ese artista, dichos por el mismo crítico (C. Ost, comunicación personal, 30 de mayo, 2013).

Desde el principio los Engelman Ost fueron conscientes de la importancia del conjunto que iban formando, refugio o prueba de un tipo de arte que no circulaba y no se exhibía, y que por tanto no era de fácil acceso y conocimiento. De ahí el carácter abierto, semipúblico, dado a su colección.

Se conocía que teníamos en nuestra casa obra de artistas contemporáneos y entonces nos llamaban por teléfono desde embajadas, o el Ministerio de Cultura, porque había personas, extranjeros, que querían venir a casa a conocer nuestra colección, porque era algo que no podían ver en ninguna otra parte. Nuestros hijos estaban un poco cansados de eso; siempre tenía que estar la casa ordenada... Entonces en un momento pudimos adquirir la parte de arriba de este local y empezamos a pensar en hacer un reciclaje para colocar la colección. Y luego pensamos también en mostrarla y en hacer exposiciones. La primera muestra que hicimos fue de Carlos Seveso. Él quería exponer, no había encontrado lugar y dijimos: «Bueno, vamos a hacerla acá» (C. Ost, comunicación personal, 30 de mayo, 2013).

El local, ubicado en Cuareim 1430, corresponde a una vieja casona en dos plantas, construida en 1840 y reciclada como sala de exposiciones en dos etapas. Primero, en 1994, se habilitó la parte de arriba, donde había un billar frecuentado por varios artistas presentes en la colección, y luego, en 2002, el reciclaje abarcó la planta baja, donde funcionó durante décadas la clínica de neurofisiología del Dr. Engelman. Entonces el lugar se transformó en un centro expositivo de tres niveles y 1.800 metros cuadrados que alberga gran parte de la colección y que funciona como centro cultural y expositivo, ya que periódicamente se realizan muestras itinerantes, así como charlas, talleres, seminarios y presentación de libros.

La exposición de Seveso mencionada se realizó en octubre de 1995. Antes, en setiembre de ese año, hubo un ciclo de conferencias sobre arte uruguayo en el que participaron artistas, críticos e historiadores uruguayos y extranjeros: Roberto de Espada, Alfredo Torres, Fernando Álvarez Cozzi, Nelson Di Maggio, Olga Larnaudie, Gabriel Peluffo, Joan van den Berge, María Luisa Torrens, Ana Tiscornia, Anhelo Hernández, Carlos Seveso, Gerardo Mosquera, Mariví Ugolino y Regine Cardis-Toulouse, Ricardo Pau-Llosa. Desde entonces las actividades fueron frecuentes y continuas, con un promedio de seis exposiciones o eventos por año, y picos de hasta diez actividades en algunos años (como en 1998 y 2007).

Entre 1996 y 2011 expusieron en la Colección más de 50 artistas, entre ellos Eduardo Cardozo, el fotógrafo Daniel Behar, Lacy Duarte (con su «Hecha la ley, hecha 
la trampa»), Javier Bassi, López Lage, David Salamanovich, el escultor Juan José Núñez, Patricia Bentancur, Federico Arnaud, Alejandra del Castillo, Fabián Oliver, Pablo Bielli, María Minetti (dos veces), Gustavo Tabares (dos veces), Juan Burgos, Santiago Tavella, Mariana Méndez, Martín Sastre, Carlos Costa, Alejandro Cesarco y Sean Partridge (dos veces), Cecilia Vignolo, Martín Pelenur, Sebastián Sáez, Jacqueline Lacasa, Cristina Casabó, Carolina Comas, Cecilia Mattos, Ana Sandleris, Santiago Velazgo, Manuel Rodríguez, Colette Hilel, Yudi Yudoyoko, Sergio, Aldo Baroffio y Ana Bidart, Gabriel Balla, Doris Rawak, Gabriel Lema, Ernesto Rizzo, Juan Uría, Roberto de León, Mercedes Bustelo, Óscar Bonilla, Karla Ferrando, Ana Campanella, Agustín Sabella, Ivonne Da Costa, Orestes Lattaro, Jessie Young, Olga Bettas, Virgina Villaplana, Marcelo Isarrualde y Ana Clara Talento.

En esos años también expusieron diversos colectivos, como el Movimiento Sexi y Alonso+Cracium, y hubo varias muestras colectivas, como «Cuatro signos» (Diego Masi, Marcelo Mendizábal, Sergio Rodríguez y Felipe Secco), «Erótica Rodelú» (con curaduría de Clío Bugel y López Lage y obras de Patricia Bentancur, Carolina Besuievsky, Alejandro Cesarco, Carolina Comas, Federico Rubio, Sylvia Meyer, Magela Ferrero, Clemente Padín, Ángela López y Sergio Porro), «Erótica urbana» (con obras de Gustavo Tabares, Javier Abreu, entre otros), «Bit bang», realizada para el Centro Cultural de España en Lima, que tenía obras de videoarte de Enrique Aguerre, Álvarez Cozzi-Pellegrino, Teresa Puppo, Juliana Rosales y Pablo Uribe, entre otros.

Los coleccionistas han realizado diversas actividades y muestras de arte en coordinación con organismos internacionales, institutos privados, de cooperación y embajadas, como el Instituto de Cooperación Internacional y luego con la Agencia Española de Cooperación (AECID), la Alianza Francesa, las embajadas checa, francesa y española, el Instituto Goethe y la Fundación Batuz. Asimismo, la sede de la Colección ha servido para ceremonias de entrega de premios de estímulo a los artistas, como el Premio Paul Cézanne, destinado a artistas emergentes, otorgado por la Embajada de Francia y en cuyo jurado participó Ost.

Presentaciones de libros ha habido varias, entre otras, de obras de Hugo Achugar (2002), Tatiana Oroño (2005), Jacqueline Lacasa (2006) y Virginia Villaplana (2010).

Muchas de las muestras individuales y colectivas se realizaron en coordinación con la FAC, y tuvieron como expositores y curadores a discípulos y docentes de esta. También con la FAC se organizaron sesiones de cine nacional y de cine experimental.

En 2009 se publicó el catálogo de la Colección Engelman Ost, que contó con el apoyo de la Agencia Española de Cooperación (AECID). Los textos, que incluyeron un análisis y una valoración de la colección, estuvieron a cargo de tres artistas y curadores cercanos a los coleccionistas: Patricia Bentancur, López Lage y Jacqueline Lacasa. Los tres han participado en distintas actividades junto con los Engelman Ost: han expuesto o curado muestras en la sede de la Colección, organizado o participado en char- 
las, e integran el acervo. Y se trata de tres figuras de peso en el campo artístico local: Bentancur fue responsable del área de artes visuales de AECID y es hoy curadora principal de Centro Cultural de España, López Lage es director de la FAC y Lacasa fue directora del Museo Nacional de Artes Visuales (2007-2009).

En el repertorio de muestras individuales y colectivas realizadas en el local de los Engelman Ost, figuran varias de artistas que no integran la colección (entre otros, Olga Bettas, Mercedes Bustelo, Gabriel Balla, Cecilia Vignolo, Cecilia Mattos, Ana Sandleris, Aldo Baroffio, Ana Campanella). Esto refleja una política de los coleccionistas de fomentar y promover el arte contemporáneo y a los artistas emergentes, más allá de su colección. Además, ceden su espacio expositivo sin pedir una obra a cambio ni cobrar, ya que todas las actividades que realizan son gratuitas.

No les pedimos nada a los artistas. No nos quedamos con obra ni les cobramos nada, como otros que cobran por metro cuadrado de pared. No lucramos con esto. Lo que podemos lo compramos y lo que no podemos no. Las actividades son todas gratis. No cobramos entrada para visitar la colección, ni cobramos para hacer un evento. Financiamos la colección con lo que reunimos en los años de trabajo. La clínica de neurofisiología que teníamos era la más prestigiosa del país. Igual no es tan costoso tener una colección cuando uno la hace así. ¡Muchas veces les comprábamos en cuotas a los artistas! (C. Ost, comunicación personal, 30 de mayo, 2013).

Las visitas a la Colección se hacen actualmente con coordinación previa, puesto que el local no tiene un horario fijo en el que se abra al público. En general, Ost prefiere acompañar a los grupos, transmitiéndoles personalmente el guion curatorial.

Desde el punto de vista museográfico, la propuesta es la de exhibir las obras sin cédulas que informen sobre su autor, nombre o fecha. Ost defiende esa decisión reivindicando el carácter privado y familiar de la colección: «Así como en mi casa no pongo etiquetas, acá tampoco». Más allá de esa explicación, la decisión puede leerse también como un intento por evitar que el espacio de la colección se asimile a un museo, donde el público puede entrar en contacto con las obras y artistas independientemente de su procedencia. En la colección Engelman Ost es al revés: el visitante conoce los datos de la obra vinculados a la experiencia de los coleccionistas con ella y su autor.

A diferencia de otros coleccionistas, Ost reivindica el carácter parcial, subjetivo y no representativo del conjunto reunido. La Colección no pretende ser un corte estratigráfico del arte producido en un momento dado en el país, por lo que no procura abarcar todas las tendencias, períodos, corrientes ni autores. 


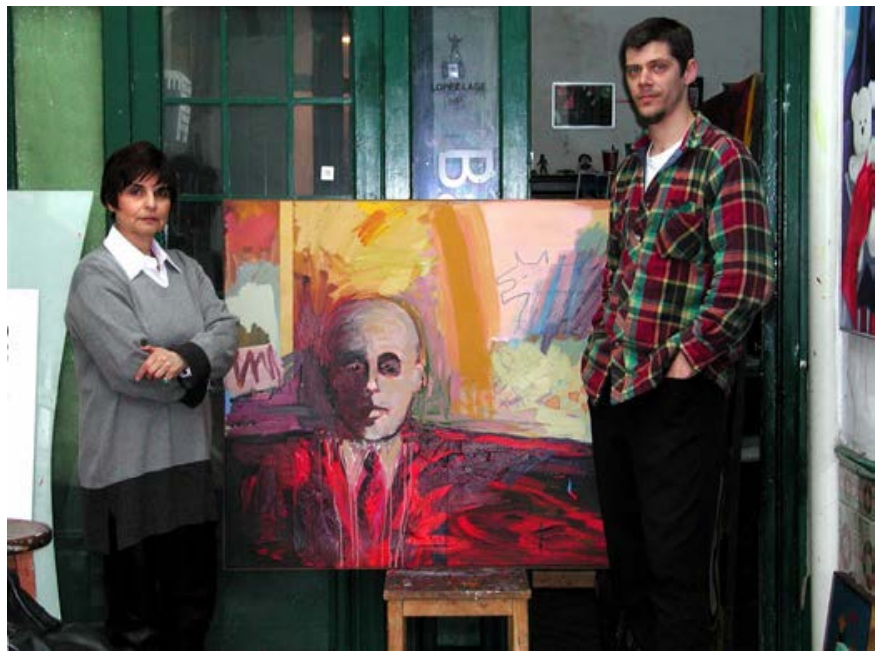

Figura 4. Clara Ost y López Lage en el antiguo taller de Longa con su autorretrato, agosto de 2002 (gentileza de la Colección Engelman Ost)

La colección abarca un marco temporal amplio, desde la actualidad hasta los años cincuenta. Estas corresponden a trabajos de abstracción geométrica de Costigliolo y Freire, que fueron los primeros artistas en ser coleccionados, aunque el perfil de la colección está muy lejos de ese lenguaje plástico. Los artistas más presentes son pintores que siguieron la línea neoexpresionista abierta por Hugo Longa (1934-1990), el creador de quien tienen mayor número de obras (más de 30). Entre ellos se destaca López Lage, discípulo de Longa, de cuyas distintas etapas creativas los Engelman Ost tienen numerosas obras. A él hay que agregar otros discípulos de Longa, como Álvaro Pemper, Margaret Whyte, Gustavo Tabares, María Clara Rossi y Teresa Puppo, así como otros plásticos cercanos a esa corriente, como Carlos Musso, Carlos Seveso, Virginia Patrone, Carlos Barea, Ernesto Vila, Eduardo Cardozo y Juan Uría, cuyas presencias son significativas en la colección.

Dentro de la escultura predomina también la línea expresionista, con artistas que exploran en el sentido y el significado de los materiales, como Hugo Nantes, Germán Cabrera, Juan José Núñez, Rimer Cardillo y Lacy Duarte. A ellos se suma Águeda Dicancro, de quien hay una instalación de gran porte.

Junto con las pinturas, esculturas e instalaciones, la colección tiene una presencia significativa del lenguaje fotográfico, con obras de Óscar Bonilla, Magela Ferreiro, Diana Mines, Federico Rubio, Álvaro, Zinno y Leo Barizzoni.

De este repertorio surge un perfil de la colección que es más expresionista que racional, más lírico que geométrico, más figurativo que abstracto. Así se consideró 
cuando fue abierta al público, en diciembre de 1994, y la crítica celebró la audacia y la osadía expresiva de los coleccionistas.

En un artículo en El País, la crítica Alicia Haber estimó que, dentro de lo que era entonces el panorama artístico local, había en la colección «una preferencia por postulaciones estéticas vinculadas al neoexpresionismo en sus disímiles variantes», y que lo primero que impactaba eran «las últimas telas de su mayor exponente, Hugo Longa». Seguidamente mencionó a Patrone, López Lage, Musso, Seveso y Duarte, para luego citar «otras vertientes de gran fuerza colorística y expresiva», como Gustavo Nacle y Nantes, para sentenciar que «cromatismo exaltado y vehemencia de las imágenes imantan la mirada del visitante».

Luego matiza esta última afirmación sosteniendo que, si bien al iniciar la recorrida parece que esa «potencia cromática» y «violencia gestual» son las características predominantes, «el panorama es mucho más matizado» («con otras estéticas más contenidas y suaves, como el collage intimista de Vila, el dibujo acromático de Marcelo Legrand, los grafismos lúdicos y líricos de Carlos Barea, el arte pobre de J.J. Núñez, la severidad melancólica de Eduardo Cardozo y el simbolismo de Álvaro Pemper» (Haber, s. f.).

Finalmente, al formular una valoración general de la colección, Haber (s. f.) considera que los criterios presentes «tienen que ver con un gusto por lo más intrépido desde el punto de vista cromático o por lo más atrevido desde el punto de vista de las imágenes», lo que marca una apuesta de consumo artístico audaz, singular en el mercado del arte de los años noventa.

Hay una afinidad con la osadía expresiva y se prefiere lo fogoso, lo impetuoso y lo febril que al espectador poco entrenado puede parecerle demasiado ríspido. Es más: en la colección Engelman-Ost hay muchas expresiones que pocos uruguayos se animan a comprar y a tener en su casa. En este país donde la mayoría de los coleccionistas [...] prefieren artistas consagrados y estéticas más moderadas, mientras la gran parte del público general ni se cuestiona: se contenta con lo más fácil, una pintura meramente decorativa de escaso espesor estético, los Engelman-Ost, en cambio, prefieren lo más riesgoso. Más allá de esta singularidad llamativa hay una constante que tiene que ver con lo más comprometido, lo más experimental, lo más juvenil y sobre todo lo creado por artistas que nada tienen que ver con las oscilaciones del mercado, las apetencias decorativas o la complacencia con el público masivo.

Más allá de los aspectos vinculados a lenguajes y temáticas, hay un hilo conductor en la colección que tiene que ver con lo vincular, con ese acercamiento entre coleccionista y artista que sin duda matrizó la colección. Ese aspecto es el que expli- 
ca la presencia de obras de Freire y Costigliolo en una colección que luego siguió otros caminos, distantes de ese lenguaje concreto y contenido.

Interrogada al respecto, Ost (comunicación personal, 30 de mayo, 2013) afirma que en su acervo hay una coherencia que vincula los temas presentes en las piezas, referidos a la identidad, la memoria y el drama humano. Y si bien reconoce que la sala dedicada a los geométricos aparece distante del resto, considera que estas obras también hablan de una sociedad y sus valores.

Nuestro guion responde a valores que nos interesa y que queremos resaltar, y que tienen que ver con la memoria. Hacemos un rescate de la memoria y de la cultura del lugar y de la época por la cual estamos transitando. Es por eso que elegimos el momento en el que vivimos para conectarnos con el artista, y no vamos para atrás, salvo en algunos casos como el de Costigliolo. Ahí nos interesaba recuperar los antecedentes de su última etapa. Pero es el momento del artista y de la sociedad lo que nos interesa capturar. Si el artista no responde a la sociedad no nos interesa, por más bueno que sea. En este país hubo grandes temas, no hablemos de problemas, que preocuparon a toda la sociedad: emigración, crisis económica, desaparecidos políticos, temas que son de este lugar pero también de proyección internacional, porque desaparecidos hubo acá, también los hubo en mi familia, que fueron hechos humo en los campos de concentración, y por eso me interesa trabajar con la memoria. Me duele mucho cuando desaparece una cultura, una generación. Entonces trato de rescatar a través de lo que vamos seleccionando, lo que se está produciendo, porque es el espejo, a través del artista, de lo que se piensa en este contexto. [...] Siempre hay un tema en torno a la obra; aun cuando se trate de los geométricos, que parece que no hay tema, en realidad hay. Allí hay un deslumbramiento frente a la ciencia en los años cincuenta, un despojamiento de la figura humana. Por algo se produce.

Más allá de esa explicación, es claro que la presencia de Costigliolo y Freire se debe al vínculo afectivo y a la enorme influencia que la antigua profesora de preparatorios ejerció sobre Ost. Ese tipo de vínculo se repitió luego con otro artista, que podría incluso verse como paterfamilias de gran parte de la colección, Hugo Longa, y tras la muerte de él, con López Lage.

Sin duda el acercamiento a Longa marcó la dirección de la colección. Se inició en una relación previa entre Longa y Engelman, quienes vivieron su juventud en Salto, y se explica en parte por una sensibilidad compartida, de preocupación por el tema de la memoria. Longa dedicó parte de su producción a denunciar las prácticas de exterminio durante el nazismo contra el pueblo judío (Testimonio sobre Ausch- 
witz, de 1967), así como la situación de los detenidos desaparecidos durante la dictadura militar en Uruguay. Varias obras de Longa adquiridas por el matrimonio (ambos de origen judío y con familiares muertos en los campos de concentración) recogen esta etapa del artista en los años ochenta, con pinturas que aluden a los crímenes de lesa humanidad, los problemas de la memoria y la verdad vinculados a la reapertura democrática.

Desde Longa surge el vínculo con un joven López Lage, que a fines de los noventa será fundador y director de la FAC. Esta se ha convertido desde entonces en una institución gravitante en el campo artístico local, como centro de formación de nuevas generaciones de artistas y como lugar de promoción e irradiación de distintas corrientes y prácticas artísticas contemporáneas. Y desde allí surgen nuevos vínculos, que a partir de los 2000 han ido ampliando el círculo de amigos y de autores coleccionados por los Engelman Ost.

Numerosos miembros, docentes y discípulos de la FAC pasaron a integran la colección en la última década, como Enrique Aguerre, Jacqueline Lacasa, Juan Burgos, Sergio Porro, Florencia Flanagan y otros más jóvenes, como Javier Abreu, Agustín Sabella o Julia Castagno, cuya obra tiene una presencia importante en la colección. Incluso el local de la Colección Engelman Ost ha funcionado como extensión de los talleres de la FAC.

La producción de esta nueva generación de artistas mantiene la línea expresionista, colorista, figurativa y subjetiva de la colección, pero a partir de nuevos lenguajes próximos al neodadá y al neopop, con recursos del cómic, el animé y elementos kitsch.

En los últimos 15 años la colección ha continuado con la apuesta arriesgada y audaz que distinguía Haber en el artículo de 1994, reuniendo prácticas artísticas típicamente contemporáneas, instalaciones, performances, con obras como las de Dani Umpi y acciones como la realizada en la sede por el colectivo Movimiento Sexy (Dani Umpi, Julia Castagno, Paula Delgado, Federico Aguirre y Martín Sastre) en setiembre de 2002, titulada Primer gran venta de garaje de arte contemporáneo, o la colectiva Arte degenerado, realizada en 2015 con participación de Fabricio Guaranga, María Mascaró, Yudi Yudoyoko, Carolina Sobrino y C. Lenkiewicz, y curaduría de Fernando Barrios. 


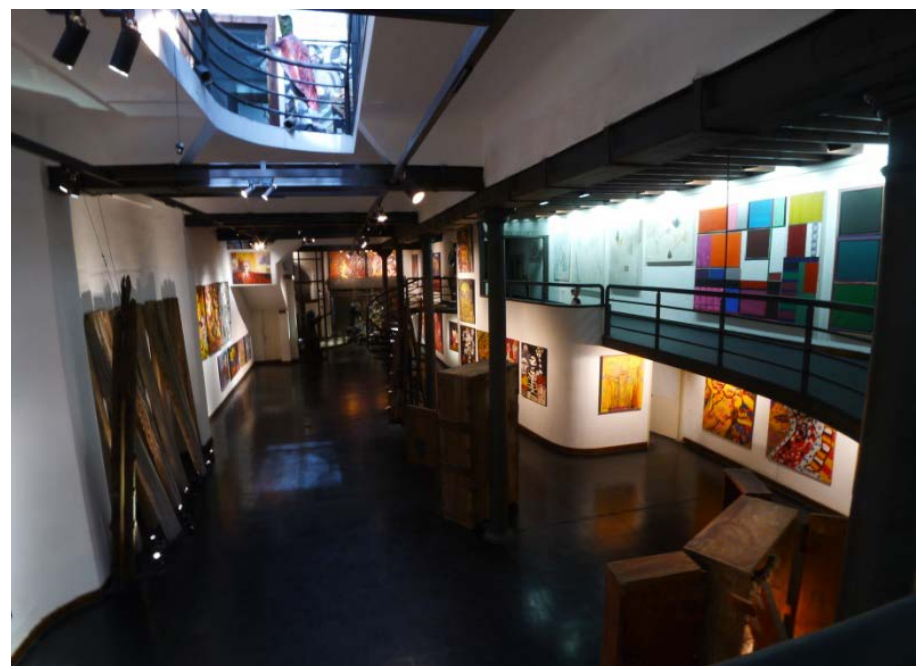

Figura 5. Vista de la Colección Engelman Ost con obras de Longa, Rimer Cardillo y López Lage, entre otros. (Gentileza Colección Engelman Ost)

\section{Consideraciones finales La colección Engelman-Ost en el campo artístico local}

Como ejemplo de coleccionismo contemporáneo, el matrimonio Engelman Ost ha reunido a lo largo de 50 años una colección privada que exhibe en su propio espacio, con una selección de obras y una propuesta curatorial que responde a inquietudes propias, surgidas de la experiencia vital de los coleccionistas y de los vínculos que han podido y querido entablar con un sector de los artistas uruguayos contemporáneos. La colección no busca ser un corte representativo del arte contemporáneo de Uruguay ni aspira a ser consagrada en el ámbito público como tal. Sus creadores eligen sus propios interlocutores-legitimadores, apoyándose en una red de amigos artistas e instituciones con los que comparten proyectos de promoción y difusión del arte que consideran válido. En ese sentido, en su actuación dentro del campo artístico local fueron tejiendo redes con determinados actores, fundamentalmente con la FAC y organismos vinculados a las embajadas de España y Francia, entre otros, con los que unieron esfuerzos para la difusión, promoción y profesionalización del arte contemporáneo local.

Más allá del carácter subjetivo dado a la colección, la estrecha relación con los artistas vinculados a la FAC ubicó a los Engelman Ost como un actor del campo local que 
ha contribuido a difundir y promover determinadas manifestaciones del arte contemporáneo. Asimismo, entre los artistas cercanos a los Engelman Ost que integran la colección, han expuesto o han realizado curadurías en la sede se ubican varias de las figuras de mayor gravitación en el campo artístico local. Algunos de ellos son curadores que tienen hoy entre 45 y 55 años y que han accedido a puestos clave en las instituciones públicas y privadas dedicadas a la divulgación y la validación del arte contemporáneo, como López Lage (FAC), Bentancur (CCE), Enrique Aguerre y Jacqueline Lacasa (MNAv), Raúl Rulfo Álvarez y Santiago Tavella (Centro de Exposiciones Subte).

En 2010 los Engelman Ost publicaron, con apoyo del CCE, un libro sobre su colección para difundir su acervo artístico (López Lage, 2010), el cual contó con la coordinación de López Lage y textos de Lacasa y Bentancur.

Asimismo, la publicación Panorama del arte contemporáneo en Uruguay (Centro de Exposiciones Subte, 2016) presentó una selección de 100 artistas realizada por un grupo de curadores-artistas elegidos por el director del Subte (Álvarez), que incluyó a Bentancur, Aguerre, Tavella y Lacasa (además de Manuel Neves), todos muy vinculados a la Colección Engelman-Ost.

De las actividades de esa red de relaciones y amistades, de vínculos con artistas e instituciones, surge una idea en torno al arte contemporáneo que merece ser mostrado, premiado, exhibido. De hecho, en la colección hay ausencias significativas de artistas contemporáneos, como los conceptualistas Mario Sagradini y Luis Camnitzer, de gran peso nacional e internacional y que sin duda tienen obras de temáticas muy cercanas a las que interesan a los coleccionistas.

Es claro que la metodología de acercamiento a los artistas perfiló la colección en una dirección que, si bien se apoya en elementos subjetivos y afectivos -empatías, círculos de amistades-, no escapa a la influencia de redes que agrupan a los artistas en torno a trayectorias, tendencias y adscripciones institucionales o de otro tipo con poder legitimador (apadrinan y otorgan visibilidad) para construir discursos sobre el arte contemporáneo que merece ser visto, reconocido y coleccionado.

Por otra parte, fue esa metodología — que prescinde de los agentes que operan en el mercado del arte- la que explica el acercamiento de los Engelman Ost a artistas que estaban en los márgenes del arte legitimado y que habilitó a los coleccionistas a cumplir un papel fundamental en la promoción de manifestaciones artísticas novedosas y de creadores emergentes. El carácter osado, audaz y comprometido que a principios de los noventa distinguió al conjunto de obras reunidas fue posible gracias a ese modelo de consumo alternativo.

Como ejemplo de nuevo coleccionismo, la colección Engelman Ost se apoyó todos estos años en una red de actores privados, desconfiando del Estado y sus instituciones (por ejemplo, en 2016 no prestó obras de María Freire para la muestra retrospectiva que realizó el Museo Departamental Juan Manuel Blanes). El Estado tampoco aparece 
para este matrimonio como legatario natural de su patrimonio artístico, como sí lo creyeron los coleccionistas modernos. «Cuando ya no estemos — dice Ost—, quisiera que se mantuviera la colección como unidad. Me gustaría que a mis hijos les fuera tan bien que pudieran seguir manejando esto desde donde estén. Ceder o donarlo al Estado no me genera confianza».

Más allá de esa desconfianza hacia lo público-estatal, estos coleccionistas sí han creído en el carácter público de sus esfuerzos en materia artística, no solo abriendo la colección al público, sino también llevando adelante o acompañando medidas de patrocinio y promoción del arte contemporáneo. De ese modo comparte con el nuevo coleccionismo artístico — tal como lo definió la historiografía argentina- esa vocación de hacer política pública desde colecciones privadas.

\section{Referencias bibliográficas}

BaldasarRe, M. I. (2006). Los dueños del arte: Coleccionismo y consumo cultural en Buenos Aires. Buenos Aires: Edhasa.

BAUdRILlard, J. (1969). El sistema de los objetos. México: Siglo XXI.

Bourdieu, P. (1989-1990). «Campo literario: Prerrequisitos críticos y principios de método». Criterios, 25-28, 20-42. Recuperado de http://www.criterios.es/pdf/ bourdieucampo.pdf.

Bourdieu, P. (1998). La distinción: Criterio y bases sociales del gusto. Madrid: Taurus.

CaEtano, G. (2010). «Ciudadanía y nación en el Uruguay del Centenario (1910-1930):

La forja de una cultura estatista». Revista Iberoamericana, 10(39), 161-176.

CEntro de Exposiciones SubTe (2016). Panorama del arte contemporáneo en Uruguay. Montevideo: Intendencia de Montevideo.

CERviÑo, M. (2011). «Nuevo coleccionismo de arte argentino contemporáneo: El caso de Gustavo Bruzzone». ASRI. Arte y Sociedad. Revista de Investifación, 0. Recuperado de http://asri.eumed.net/0/mc.html.

CHARTIER, R. (1992). El mundo como representación: Estudios sobre historia cultural. Barcelona: Gedisa.

DANTo, A. (1964). «El mundo del arte». Journal of Philosophy, 61(19), 571-584. Recuperado de http://eva.fhuce.edu.uy/file.php/515/El-Mundo-Del-Arte-Arthur-Danto.pdf.

DickIE, G. (2005). El círculo del arte: Una teoría del arte. Barcelona: Paidós.

GiuntA, A. (coord.). (2009). Museos y coleccionismo ante el desafío del Bicentenario. Buenos Aires: ArteBA.

Haber, A. (s. f.). «Engelman Ost expone a los creadores de nuestro país». El País. 
Lemus, F. (2014). «Desde el afecto y por la historia: Aproximaciones a la colección Bruzzone». Boletín de Arte, 14(14), 49-55. Recuperado de http://papelcosido. fba.unlp.edu.ar/ojs/index.php/boa.

LÓPEZ LAGE, F. (2010). Arte contemporáneo uruguayo: Colección Engelman-Ost. Montevideo: Centro Cultural de España, Colección Engelman-Ost.

Muensterberger, W. (1993). Collecting: An unruly passion. Psychological perspective. Nueva Jersey: Princeton Legacy Library.

PACHECO, M. (2002). «Nuevas tendencias en el coleccionismo argentino de los noventa». En M. C. RAmírez y T. PAPANIKOLAs (eds.), Collecting Latin American art for the 21 st century. Houston: Museum of Fine Arts.

Porley, C. (2017). El origen privado de las colecciones públicas de arte: Fernando García y su legado al estado uruguayo (tesis de maestría). Universidad de Montevideo, Montevideo. 